\title{
Strain pattern in the upper facial skeleton: Preliminary model development
}

\author{
Cory Scot Goldberg BSc MD, Jeffrey Allan Fialkov MSc MD FRCSC
}

CS Goldberg, JA Fialkov. Strain pattern in the upper facial skeleton: Preliminary model development. Can J Plast Surg 2002;10(1):27-31.

In the human upper facial skeleton, the patterns of strain caused by physiological loading are not known. It is generally accepted that these patterns can be predicted based on the morphology of the bone, but this is not necessarily the case. The elucidation of these patterns of strain has a significant impact on the plating techniques of facial fractures, the development of bone substitutes and tissue-engineered bone, and the understanding of facial development. The goal of this study was to initiate the development of a model that could be used to measure strain magnitude and direction in the upper facial skeleton from physiological loading of facial musculature.

A strain gauge was bonded to the lateral orbital rim of a cadaveric skull that had been dissected, leaving only muscular origins and insertions intact. Braided nylon straps were sutured to the origins and insertions of the masseter and levator labii superioris, and these were pulled individually using a hydraulic testing machine. When the masseter origin was pulled, the recorded strain increased with increasing force and the angle of the strain corresponded directly to the angle of pull. When the levator labii superioris origin was pulled, the angle of strain was directed anteriorly and inferiorly, but did not correspond with the axis of the muscle or the axis of the lateral orbital rim where the strain gauge was located.

It was concluded that this model is reliable and reproducible for investigating strain magnitude and direction in the human upper facial skeleton.

\section{Modèles de tension dans la région crâniofaciale supérieure : Élaboration d'un modèle préliminaire}

RÉSUMÉ : Dans la région crâniofaciale supérieure de l'humain, les modèles de la tension causée par la surcharge physiologique sont inconnus. En général, il est accepté que ces modèles peuvent être prédits d'après la morphologie de l'os, mais ce n'est pas nécessairement le cas. L'élucidation de ces modèles de tension a des répercussions importantes sur les techniques de pose de plaque en cas de fractures faciales, sur le développement de substituts osseux et d'os issu du génie tissulaire et sur la compréhension du développement facial. La présente étude visait à amorcer un modèle qui pourrait être utilisé pour mesurer l'ampleur et la direction de la tension dans la région crâniofaciale supérieure, d'après la surcharge physiologique de la musculature faciale.

Un tensiomètre a été fixé au rebord orbital latéral du crâne d'un cadavre disséqué pour ne laisser que les origines et les insertions musculaires intactes. Des bandes de nylon tressées ont été suturées aux origines et aux insertions du masséter et du muscle releveur de la lèvre supérieure, qui ont été tirées individuellement au moyen d'une machine d'essai hydraulique. Lorsque l'origine du masséter a été tirée, la tension inscrite a augmenté avec une force croissante, et l'angle de tension correspondait directement à l'angle de traction. Lorsque l'origine du muscle releveur de la lèvre supérieure a été tirée, l'angle de tension allait dans une direction antérieure et inférieure, mais ne correspondait pas à l'axe du muscle ou du rebord orbital latéral où le tensiomètre était fixé.

On a conclu que ce modèle est fiable et reproductible pour explorer l'ampleur et la direction de la tension dans la région crâniofaciale supérieure de l'humain.

Key Words: Craniofacial; Human; Strain; Strain gauge

Sunnybrook $\mathcal{E}$ Women's College Health Sciences Centre, Division of Plastic Surgery, University of Toronto, Toronto, Ontario

Correspondence: Dr Jeffrey A Fialkov, Sunnybrook Health Sciences Centre, 2075 Bayview Avenue M1-519A, Toronto, Ontario M4N 3M5.

Telephone 416-480-4257, fax 416-480-4224, e-mail jeff.fialkov@swchsc.on.ca 
$\mathrm{T}$ he human facial skeleton can be divided into upper and lower segments. The upper segment, composed of the frontal bone, zygoma, maxilla and nasal bone, has complex morphology and relatively static articulations. The upper facial skeleton (UFS) houses and protects organs of special sense, protects the airways, and serves as a foundation for facial mimetic musculature. Strain in the UFS may result from forces that are transmitted indirectly from the mandible and transmitted directly from the pterygoid and masseter muscles, and from the facial mimetic muscles.

Wolff's law states that bony remodelling and, consequently, morphology, are a result of forces applied to the bone (1). Anecdotally, it has been reported that tension applied to bone is osteogenic, while compression is resorptive (2).

The implication of Wolff's law is that morphology of bone can predict the strain pattern that results from physiological loading by the musculature.

In fact, strain patterns are not entirely predictable based on the morphology and vector of muscle loading. Teng and Herring (3) examined the strain pattern of the miniature pig zygomatic arch during mastication. Although the majority of force on the zygomatic arch results from mas-

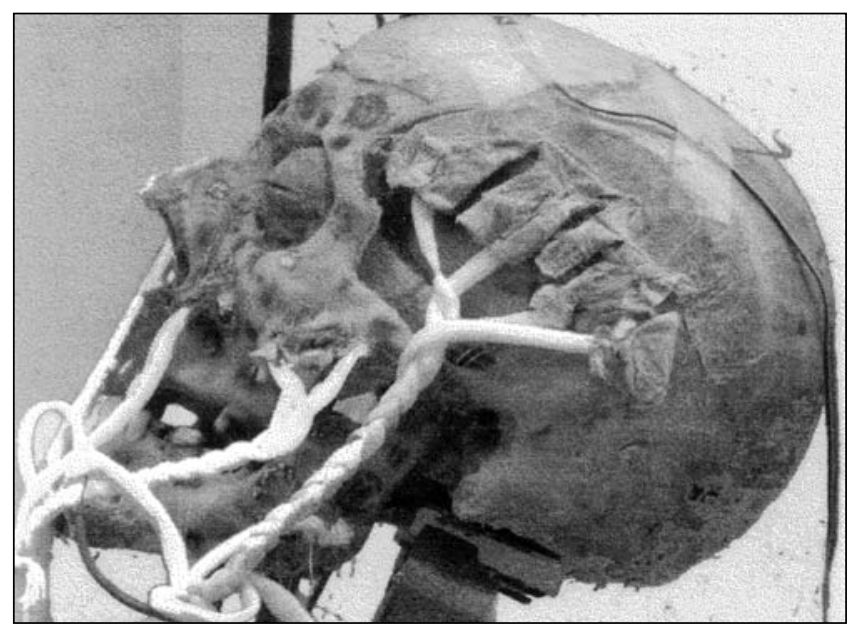

Figure 1) A dissected cadaveric skull with braided nylon straps sutured to muscular origins and insertions

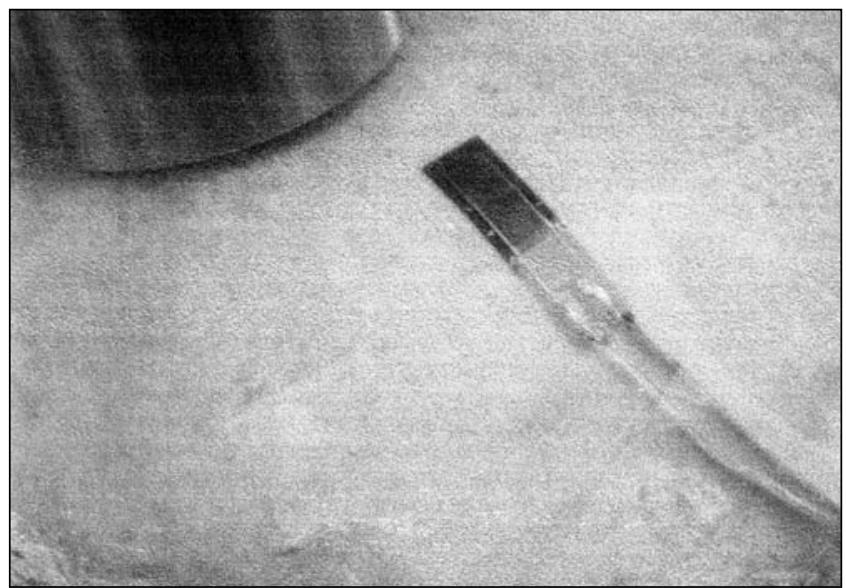

Figure 2) A compressive load was applied to the cranial vault and the resultant strain was measured $2 \mathrm{~cm}$ away by a uni-axial strain gauge seter muscle contraction, the authors found that the strain vector along the zygomatic arch did not correspond to the angle of pull by the masseter, and that the angle of strain was different at the anterior and posterior aspects of the arch.

There are several reasons why strain patterns in the UFS are unpredictable. First, the bony structure and musculature are extremely complex. Second, cranial and facial sutures act to dissipate and redirect loads $(3,4)$. Finally, some masticatory muscles exert a large compressive load against their bones of attachment (4).

The treatment of facial fractures is aimed at stabilizing the three-dimensional anatomy of the facial skeleton (5). Plating techniques are directed by strain patterns that are predicted based on morphology alone, namely the buttresses of the facial skeleton. Thus, although the strain patterns in the UFS have an impact on plating techniques, and the development of bone substitutes and engineered bone, these patterns are unpredictable and unknown. The objective of this study was to initiate the development of a reliable and reproducible model to evaluate strain patterns in the human UFS.

\section{METHODS}

A single preserved human cadaveric skull was dissected, leaving facial mimetic and masticatory muscle origins and insertions intact. Braided nylon straps were sutured to these origins and insertions (Figure 1). A single uni-axial strain gauge ( $350 \Omega \pm 0.15 \%$, [A-Tech Instruments Ltd, Canada]) was bonded to the cranial vault (Figure 2). Additionally, several tri-axial strain gauges (stacked, rectangular $350 \Omega \pm$ $0.15 \%$ ) were bonded to the skull in strategic locations after the surfaces had been meticulously cleaned (Figure 3). The skull was mounted on an Instron 8501 servo-hydraulic uni-

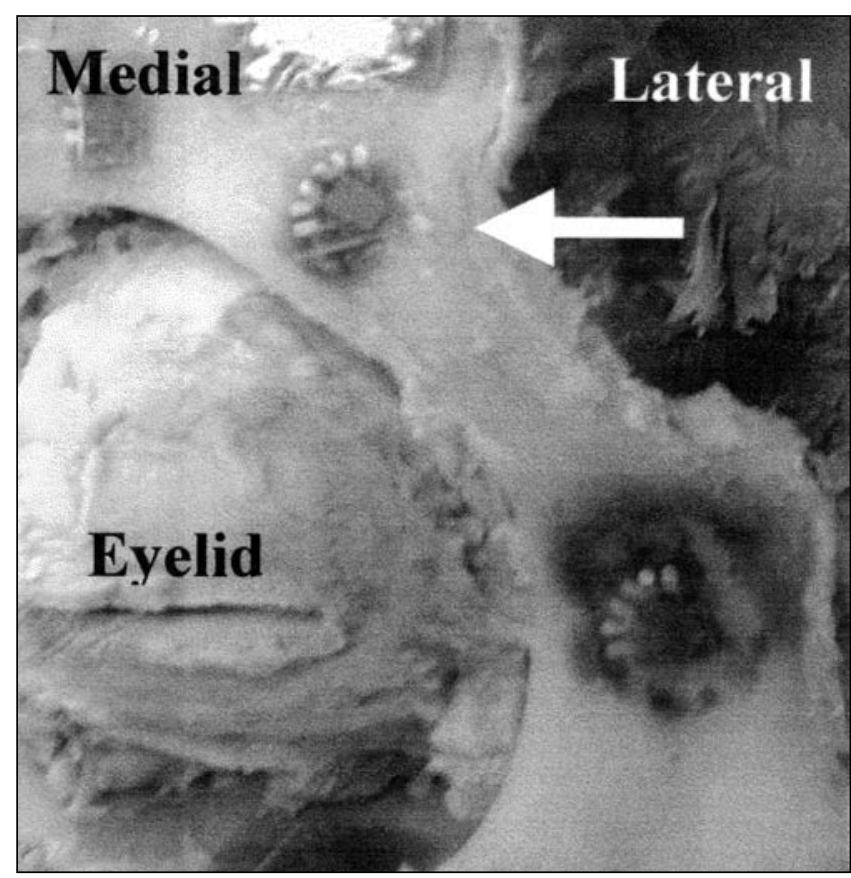

Figure 3) A single tri-axial strain gauge (arrow) located on the lateral orbital rim with $0^{\circ}, 45^{\circ}$, and $90^{\circ}$ angles 


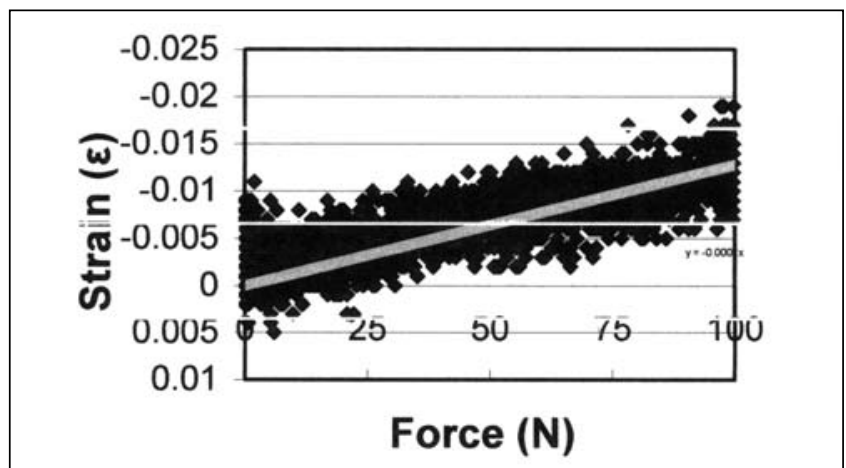

Figure 4) Force versus strain. Measurements were recorded $2 \mathrm{~cm}$ away from the compressive load on the cranial vault. The relationship is linear, with a maximum strain of $13 \mu \varepsilon$ at $100 \mathrm{~N}$

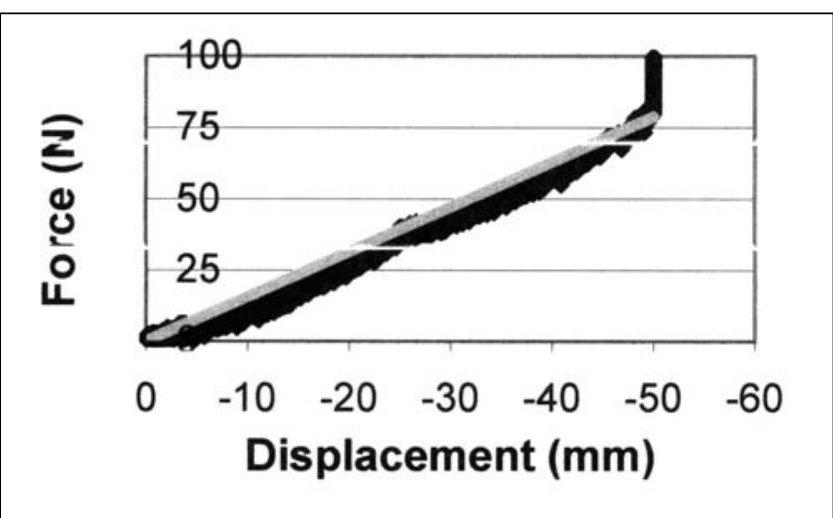

Figure 5) Displacement of the actuator versus force shows a linear relationship when pulling on the masseter origin. This linear relationship confirms the integrity of the nylon straps and musculotendinous origins, which were able to reliably transmit forces to the skull

TABLE 1

Summary of strain magnitudes and angles

\begin{tabular}{|c|c|c|c|c|c|}
\hline \multirow[b]{2}{*}{$\begin{array}{l}\text { Compressive } \\
\text { load (N) }\end{array}$} & \multirow[b]{2}{*}{$\begin{array}{c}\text { Control } \\
(\mu \varepsilon)\end{array}$} & \multicolumn{2}{|c|}{ Masseter } & \multicolumn{2}{|c|}{$\begin{array}{c}\text { Levator labii } \\
\text { Superioris }\end{array}$} \\
\hline & & $\begin{array}{c}\text { Strain } \\
\text { magnitude }(\mu \varepsilon)\end{array}$ & $\begin{array}{l}\text { Strain } \\
\text { angle }\end{array}$ & $\begin{array}{c}\text { Strain } \\
\text { magnitude }(\mu \varepsilon)\end{array}$ & $\begin{array}{l}\text { Strain } \\
\text { angle }\end{array}$ \\
\hline 10 & 1 & 18 & $315^{\circ}$ & 16 & $234^{\circ}$ \\
\hline 25 & 3 & 26 & $301^{\circ}$ & 22 & $231^{\circ}$ \\
\hline 100 & 13 & 37 & $244^{\circ}$ & $\mathrm{N} / \mathrm{A}$ & $\mathrm{N} / \mathrm{A}$ \\
\hline
\end{tabular}

The strain from a compressive load on the cranial vault was small, even when recorded only $2 \mathrm{~cm}$ away. The angle of strain from pulling the masseter rotated due to a changing angle of pull by the Instron

axial testing machine (Instron Corporation, United States). LabView (National Instruments, United States) software was used to convert the data from the gauges to a measurement of strain. First, the skull was mounted on the Instron by using a universal mount clamped to the foramen magnum, and a compressive load from 0 to $100 \mathrm{~N}$ was applied to the cranial vault $2 \mathrm{~cm}$ away from the uni-axial strain gauge (Figure 2). This compressive loading was used as a control to examine the dissipation of forces in the cranial vault.

Second, the skull was inverted and mounted on the Instron using a universal mount clamped to the skull by means of a burr hole in the vertex. A force was then applied to the skull via the nylon straps along the line of pull for each muscle that was being tested. Two muscle origins were selected: the origin of the masseter (tested up to $100 \mathrm{~N}$ ), and the origin of the levator labii superioris (tested up to $30 \mathrm{~N}$ ). The resultant strain was recorded using a tri-axial strain gauge located on the orbital rim (Figure 3). Using basic algebraic and geometric principles, the recorded strains from the three axes of the gauge were resolved into a strain vector including both the magnitude and direction of the strain. By convention, the angle of strain is described by an angle relative to the positive direction of the horizontal axis (x-axis), with a counterclockwise direction that is taken to be positive (6).
Control

\section{RESULTS}

Compression loading of the cranial vault was performed as a control. The relationship between the applied compressive force and the resultant strain was linear (Figure 4, Table 1).

\section{Origin of masseter}

The relationship of force to the displacement of the Instron actuator was linear (Figure 5). The strain magnitude and angle were measured and recorded at the lateral orbital rim after applying a force to the masseter origin (Table 1, Figure 6).

Origin of levator labii superioris

The strain magnitude and angle were measured and recorded at the lateral orbital rim after applying a force to the levator labii superioris origin (Table 1, Figure 7).

\section{Control}

\section{DISCUSSION}

The measured strain in the cranial vault was related linearly to the applied force, which confirms the efficacy of the bonded strain gauges on the bone (Figure 4). Also, the maximum measured strain was $13 \mu \varepsilon$ when $100 \mathrm{~N}$ was applied from only $2 \mathrm{~cm}$ away (Table 1 ). This small strain indicates that the cranial vault is very efficient at dissipat- 


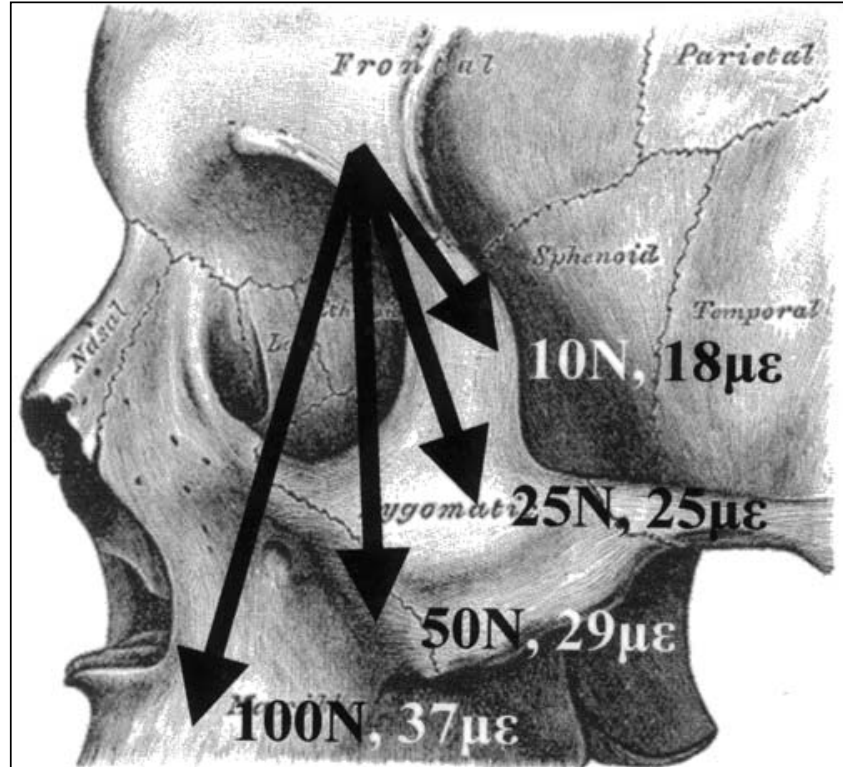

Figure 6) Diagram of strain recorded at the lateral orbital rim by applying tensile force to the origin of the masseter muscle on the zygomatic arch. The magnitude of strain increased as the force increased, but the angle rotated clockwise from $315^{\circ}$ to $244^{\circ}$

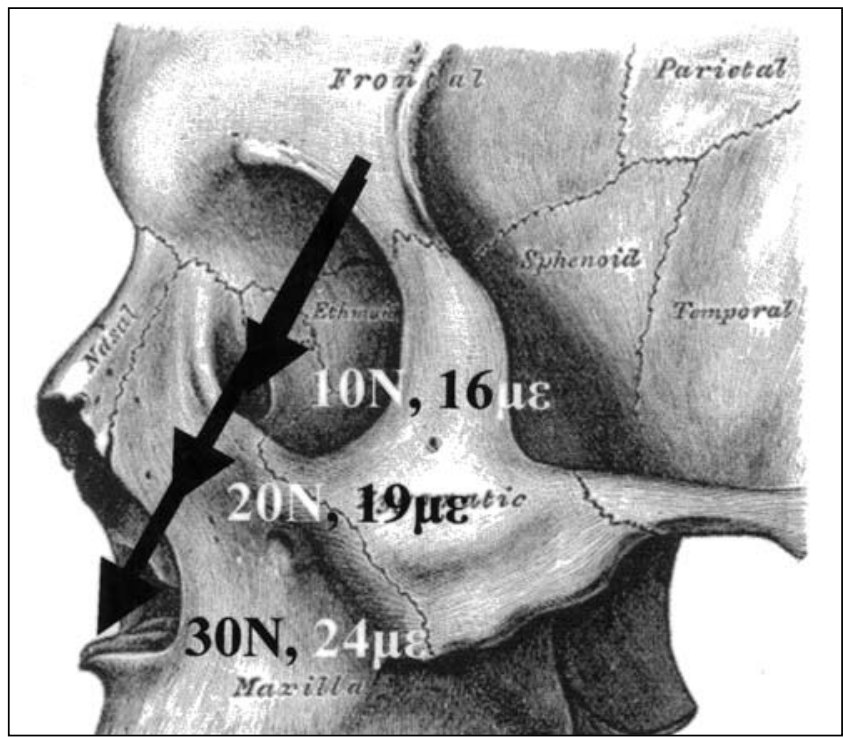

Figure 7) Diagram of strain recorded at the lateral orbital rim by applying tensile force to the origin of levator labii superioris. The magnitude of strain increased as the applied force increased, and the angle remained constant (average $230^{\circ}, \mathrm{SD} \pm 4.9^{\circ}$ ). This angle does not correspond to the line of pull on the muscle or to the morphological axis of the orbital rim

ing applied force and, thus, any force applied to the cranial vault will result in minimal strain in the UFS. Consequently, the use of a clamp applied to the vertex of the skull did not cause any significant alteration in the strain pattern in the UFS.

\section{Muscle origins}

Origin of masseter: The applied force was related linearly to the displacement of the actuator (piston), which confirms the integrity of the nylon straps and musculotendi-

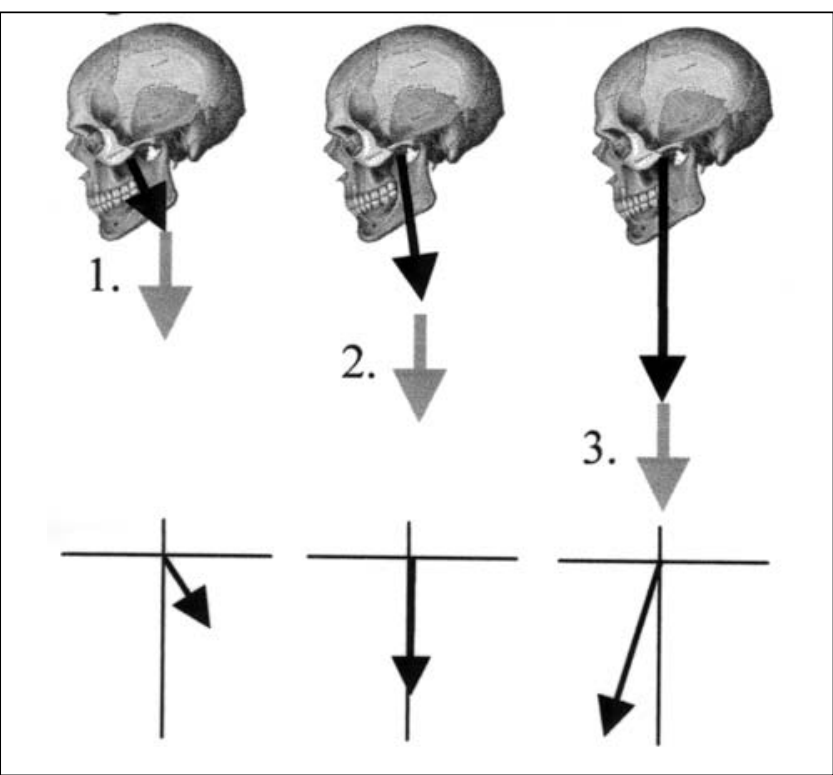

Figure 8) Diagrams 1, 2 and 3 show a progression of the vector of pull on the masseter origin as the Instron actuator moved away from the skull. During the testing of the masseter origin, the skull was positioned such that as the actuator (gray arrows) moved away from the skull the angle of pull (black arrows) changed. The recorded strain angle correspondingly rotated clockwise (shown at bottom)

nous origins (Figure 5). The measured strain at the orbital rim increased with the applied force (Table 1, Figure 6). The calculated angle of the strain decreased linearly from $315^{\circ}$ (at $10 \mathrm{~N}$ ) to $244^{\circ}$ (at $100 \mathrm{~N}$ ). Retrospectively, it was determined that the way that the skull was mounted on the Instron machine resulted in a changing direction of pull from the actuator. This happened because, as the actuator moved away from the skull to apply increasing force, the angle of pull changed. Thus, the resultant angle of strain also changed accordingly (Figure 8). Although this was an unintentional occurrence, it demonstrated conclusively that the measured strain varied in accordance with the force that was applied and, thus, it accurately reflected the direction of the strain.

Origin of levator labii superioris: As force was applied to the origin of levator labii superioris, the angle of strain decreased minimally from $255^{\circ}$ to $234^{\circ}$ as the force increased from 0 to $10 \mathrm{~N}$. As soon as the nylon-musculoendinous system was tight, between 10 and $30 \mathrm{~N}$, the angle of the strain was consistent and averaged $230^{\circ}$ $\left(\mathrm{SD} \pm 4.9^{\circ}\right)$. Importantly, this angle did not parallel the angle of pull of the levator labii superioris, which was approximately $260^{\circ}$, nor did it parallel the morphological axis of the orbital rim, which was approximately $300^{\circ}$. Thus, by applying tension to the origin of levator labii superioris, the resultant strain vector in the lateral orbital rim did not reflect the angle of pull or the structural axis of the bone. Therefore, the actual strain vector would not be consistent with predictions made based on morphology and direction of muscle loading. 


\section{CONCLUSIONS}

By using a cadaveric skull, the integrity of the muscular origins and insertions were weakened; however, this did not result in any mechanical failures in the system. Gurdjian and Lissner (7), who looked at biomechanical properties of dry, preserved and living animal skulls, concluded that the magnitude, direction and general distribution of strain patterns in preserved skulls were no different than those in skulls of living animals. Thus, strain measurements from this model, which used preserved human skulls, are applicable to skulls of living people.

One limitation of this model is that the Instron machine can apply force to only one muscle at a time. As a result, this system does not accurately depict the in vivo situation of synchronous muscle loading. Ultimately, the authors hope to gather and integrate multiple measurements of strain from this model to generate a more accurate repre-

\section{REFERENCES}

1. Murray W, Miller W. Stress-strain analysis and stress-strain relations. In: Murray W, Miller W, eds. The Bonded Electrical Resistance Strain Gage: An Introduction. New York: Oxford University Press, 1992:42-89.

2. Cordey J, Gautier E. Strain gauges used in the mechanical testing of bones. Part I: Theoretical and technical aspects. Injury 1999;30(Suppl 1):A7-13.

3. Teng S, Herring SW. Compressive loading on bone surfaces from muscular contraction: an in vivo study in the miniature pig, Sus scrofa. J Morphol 1998;238:71-80. sentation of in vivo strain patterns. To accomplish this, strain direction and magnitudes from multiple standardized points in the facial skeleton of several cadaveric skulls are required.

It can be concluded from this preliminary study that the use of strain gauges to measure strain patterns in the human UFS is possible, and that it yields results that are reliable and reproducible. Furthermore, the results confirm the accuracy and integrity of the system for both magnitude and direction of the measured strains. Initial measurements also confirm that the strain patterns in the UFS are indeed unpredictable from bone morphology and direction of muscle pull alone and, therefore, underscore the need for this information to be collected.

ACKNOWLEDGEMENTS: This study was funded in part by the University of Toronto Dean's Fund.

4. Herring SW, Teng S, Huang X, Mucci RJ, Freeman J. Patterns of bone strain in the zygomatic arch. Anat Rec 1996;246:446-57.

5. Behrents RG, Carlson DS, Abdelnour T. In vivo analysis of bone strain about the sagittal suture in macaca mulatta during masticatory movements. J Dent Res 1978;57:904-8.

6. Rudderman RH, Mullen RL. Biomechanics of the facial skeleton. Clin Plast Surg 1992;19:11-29.

7. Gurdjian E, Lissner H. Deformation of the skull in head injury. A study with the "stresscoat" technique. Surg Gyn Obst 1945;81:679. 